\title{
The Association between Estrogen and Progesterone Receptors Expression with the Stages of Endometrioid type Ovarian Carcinoma at Sanglah General Hospital, Bali, Indonesia: A Preliminary Study
}

\author{
I Gusti Ayu Sri Mahendra Dewi*, Ni Putu Ekawati \\ Department of Pathology Anatomy, Faculty of Medicine, Udayana University, Sanglah General Hospital, Bali, Indonesia
}

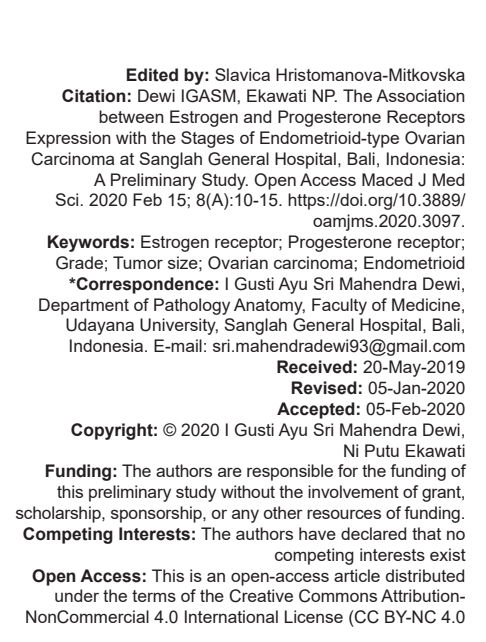

Abstract

BACKGROUND: Ovarian cancer is the most common cause of death among gynecologic malignancies. Poor prognosis is mainly due to the high incidence of advanced stage at the time of diagnosis as well as low estrogen receptor $(E R)$ and progesterone receptor $(P R)$ expression. Based on it, further understanding is needed to predict the course of disease.

AIM: This study aims to evaluate the expression of ER and PR with the stages of endometrioid-type ovarian carcinoma as the more frequent type carcinoma at Sanglah General Hospital, Bali.

METHODS: An analytical cross-sectional study was conducted among 36 samples of endometrioid-type ovarian carcinoma examined at Anatomical Pathology Laboratory, Faculty of Medicine, Udayana University/Sanglah Genera Hospital, Denpasar. The histopathological diagnosis, grade, and tumor size, as well as determination on hematoxylineosin staining were assessed. The expression of ER and PR was examined using immunohistochemical stain. Data were analyzed using the SPSS version 15 software for risk analysis and $p<0.05$ was assumed statistically significant. RESULTS: Most of the samples were from 41 to 50 years of age group (41.7\%) and the average age was $51.1 \pm$ 9.80 years old. Based on the degree of differentiation, Grade 2 was the most common cases (38.9\%). However, the tumor size assessment revealed that T3 was predominant (41.7\%). Positive ER and PR expressions were obtained in 18 samples $(50.0 \%)$ and 14 samples $(38.9 \%)$, respectively. Fisher's exact test showed a significant association between ER expression with grade (odds ratio [OR]: 6.25; 95\% confidence interval [CI] 1.327-29.432; $p=0.018$ ) and tumor size (OR: $4.375 ; 95 \% \mathrm{Cl} 1.027-18.629 ; \mathrm{p}=0.043$ ). A similar findings also found in PR expression with grade (OR: 15.60; 95\% Cl 1.728-140.829; $p=0.004$ ) and tumor size (OR: 6.12; 95\% Cl 1.394-26.876; $p=0.016$ ).

CONCLUSION: ER and PR expressions are significantly associated with grade and tumor size in the endometrioidtype ovarian carcinoma.

\section{Introduction}

Ovarian cancer is the seventh most cancer, occurring around $3 \%$ of all malignancies in the woman and is the leading cause of death in gynecological malignancies [1]. Among malignancies in the female genital tract, ovarian cancer ranks after cervical and endometrial cancer. It is estimated that around 190,000 new cases and 114,000 deaths from ovarian cancer occur every year [2]. One thing that causes poor prognosis is the high incidence of tumors at an advanced stage when the diagnosis is established, which is about $75 \%$ of all patients diagnosed at FIGO Stage III or IV, as a staging system in ovarian cancer [2]. A more in-depth study about the prognostic factors as well as more integrated patient management is needed.

There are various theories of tumorigenesis of ovarian cancer, one of which is hormonal effects [3], [4], [5]. Several factors have been evaluated from hematological markers until particular surface receptor expression to assess the prognostic of cancers [4], [5]. The study on estrogen receptor (ER) and progesterone receptor $(\mathrm{PR})$ in breast and endometrial malignancies has been carried out and has been known to have relevance in therapy and prognostic [4]. This is different from ovarian cancer, where there is still a lack of data regarding ER and PR expression to ovarian cancer, and the results are even contradictory [6]. The clinical trial study, subtype determination, and biomarker status are needed to determine whether hormone receptor status in ovarian carcinoma can predict the response to endocrine therapy whether it can be used as a guideline for personal therapy for ovarian cancer [7]. Only $15 \%-18 \%$ of ovarian cancers with ER-positive responds to anti-estrogen treatment by inhibiting estrogen binding with ER. On the contrary in breast cancer, anti-estrogen treatment is effective in about $50 \%$ of patients. The most common mechanism for causing resistance to anti-estrogen therapy is the absence of ER [2]. Different study designs and sample sizes could cause these discrepancies. 
The ovary has three main histological compartments, namely: Mullerian or coelomic surface epithelium, sex cord-stromal cell, and pluripotent germinal cells [8]. In developing countries, more than $90 \%$ of malignant ovarian tumor origin from epithelium, 5\%-6\% sex cord-stromal tumor, and $2 \%-3 \%$ from germinal cells. Epithelial ovarian cancer is a heterogeneous disease, with several histological subtypes, which differ in terms of origin, pathogenesis, molecular changes, risk factors, gene expression, and prognosis [3], [7], [9]. Based on histopathology evaluation, ovarian neoplasms that fall into the category of surface epithelial tumors are serous tumor, mucinous tumor, endometrioid tumor, clear cell tumor, Brenner tumor, seromucinous tumor, and undifferentiated carcinoma [10]. Besides, the ovarian carcinoma also could be classified based on the expression of particular surface receptor. The previous study found that ER and PR expression differed between ovarian cancer subtypes [6], [11]. The proportion of tumors that were positive for PR was found to be highest in endometrioid-type carcinoma (67\%), whereas positive ER with positive $\mathrm{PR}$ was also found to be highest in the endometrioid type $(82 \%)$ [11]. However, the study did not assess further the relationship between positive expression of $P R$ and $E R$ in the progression of endometrioidtype carcinoma. The expression of ER and PR is different in various grades and stage ovarian cancer. ER and PR expressions are also can be used as an independent prognostic marker for patient survival, i.e. the positive expression can increase the patient survival rate [11].

Based on those as mentioned earlier, the purpose of this study is to investigate the association between the expression of ER and PR with the severity of endometrioid-type ovarian carcinoma at Sanglah General Hospital, Bali, Indonesia, as a preliminary study.

\section{Materials and Methods}

\section{Study design}

A cross-sectional analytic observational study was conducted during the year 2018 among surgical tissue of respondents who were diagnosed with endometrioid-type ovarian carcinoma. All of patients who had undergone biopsy were taken based on medical records using consecutive sampling technique approach.

\section{Sample collection process}

The samples of this study were surgical tissue of patients with endometrioid-type ovarian carcinoma, whose tissues were examined at the Anatomical Pathology Department, Faculty of Medicine, Udayana University/Sanglah General Hospital which corresponds to inclusion and exclusion criteria. Samples were collected on a consecutive basis until the required samples size was met. There were 36 samples enrolled in this study.

\section{Histopathological examination}

This study was conducted at the Anatomical Pathology Department, Faculty of Medicine, Udayana University/Sanglah General Hospital. The specimens were consisted of histological preparations derived from patients treated for ovarian carcinoma. The samples of specimen were fixed in $10 \%$ buffered formalin phosphate. Paraffin blocks were cut into sections with a thickness about 3-4 $\mu \mathrm{m}$. The collecting sections were stained with hematoxylin and eosin to identify the type of carcinoma (WHO classification) and histological grade of malignancy. All specimens were evaluated using light microscopy in $\times 100$ magnification. Degree of differentiation in this study was evaluated into two categories: Low grade ( $\leq$ Grade 2 ) and high grade (>Grade 2). In addition, the tumor size also divided into two categories: $\mathrm{T} 1$ and $\geq \mathrm{T} 2$.

\section{and $P R$}

\section{Immunohistochemical evaluation of ER}

The paraffin-embedded tissues from surgery tissue of patients that have been diagnosed histopathologically with endometrioid-type ovarian carcinoma were examined immunohistochemically. To determine the expression of steroid receptors, monoclonal antibodies against receptors for estrogen (Cell Marque Rabbit Monoclonal Antibody ER (EP1), 1:50 dilution) and PR (Cell Marque Rabbit Monoclonal Antibody PR (Y85) Vantagebio, 1:400 dilution) were used. The following steps were as follows: (1) Incubated the section in an incubator at $60^{\circ} \mathrm{C}$ overnight and then dewaxed, (2) reveal the epitope by heating slides in a buffer for $40 \mathrm{~min}$, (3) the preparations were left at room temperature for $20 \mathrm{~min}$, (4) preparations were rinsed in buffer, and then, endogenous peroxidase was blocked in $3 \% \mathrm{H}_{2} \mathrm{O}_{2}$ and incubated with an appropriate antibody, (5) preparations were rinsed in a buffer for $10 \mathrm{~min}$ and then incubated with the reagent (Visualization Reagent) for $30 \mathrm{~min},(6)$ washed in TBS (Tris-buffered saline, Code: S1968) $\mathrm{pH}$ 7.5-7.6 for 10-15 min, and (7) incubated with 3,3'-diaminobenzidine (substrate chromogen solution) for $10 \mathrm{~min}$ to visualize the color reaction.

The results interpretation was determined using Allred SCORING SYSTEM. As per the Allred score for ER and PR nuclear positivity, the proportion score (PS) (0-5) and the \% positive tumor cells are, 
respectively, $0(0 \%), 1(<1 \%), 2(1-10 \%), 3(11-33 \%)$, $4(34-66 \%)$, and $5(67-100 \%)$. The intensity of staining (IS) for the nuclear positivity of the cells graded as 0 , 1,2 , and 3 was as none, mild, moderate, and strong, respectively. Hence, the total scores for ER and PR are given as TS $=$ PS + IS. TS 0 and 2 are negative scores, and 3, 4, 5, 6, 7, and 8 are positive scores. In summary, the positive expression of ER and PR receptor on endometrioid-type ovarian carcinoma in this study was investigated, if $>10 \%$ positive cells after $\mathrm{IHC}$ per field was viewed. Less than $10 \%$ indicate for negative expression.

\section{Statistical analysis}

A descriptive characteristic of the data subject was tabulated. The Shapiro-Wilk test was performed to determine the normality of the data, and the Levene's t-test was performed to find homogeneity and equality. Due to data were not normally distributed, a Fisher's exact test was performed to determine the correlation between ER and PR expressions with a degree of differentiation and the size of the tumor as well as risk analyses using odds ratio (OR). Statistical significance was determined if $p<0.05$ with $95 \%$ confidence interval $(\mathrm{Cl})$.

\section{Results}

The characteristics of the respondents with endometrioid-type ovarian carcinoma used in this study are summarized in Table 1 based on age, degree of differentiation, tumor size, and expression of $E R$ and PR. The study found that the average age of respondents was $51.08 \pm 9.80$ years old. Furthermore, it can also be classified into several groups, whereas the group of 41-50 years old was predominant $(41.7 \%)$. Based on the degree of differentiation, Grade 3 was the most common cases $(41.7 \%)$. In addition, the tumor size also had the highest number in T3 group (41.7\%) followed by $50 \%$ for ER expression and $38.9 \%$ for PR expression (38.9\%). Normality test using Shapiro-Wilk suggested that all of the variables mentioned above, except for age, were not normally distributed $(p<0.05)$.

The degree of differentiation was reclassified further into $\leq$ Grade 2 and $>$ Grade 2 to determine the risk between ER and PR expression with the grading of endometrioid-type ovarian carcinoma using OR. There was 15 (65.2\%) positive ER expression in Grade 2 or below and approximately $13(56.5 \%)$ of cases also showing a positive PR expression. Risk analysis was conducted using Fisher's exact test and OR due to data was not normally distributed. The recent findings revealed that ER and PR expressions were significantly higher in the Grade 2 or below ( $p<0.05$ ) where ER expression was $6.25(95 \% \mathrm{Cl}$ : 1.327-29.432) times higher in the low grade ( $\leq$ Grade 2 ) compared with high grade ( $>$ Grade 2 ) degree of differentiation group. A similar result was also found in PR expression whereas $15.60 \quad(1.728-140.829)$ times higher in Grade 2 or below (Table 2).

Table 1: Baseline characteristic of respondents with endometrioid-type ovarian carcinoma

\begin{tabular}{|c|c|c|c|}
\hline \multirow[t]{2}{*}{ Variables } & \multicolumn{2}{|c|}{ Assessment } & \multirow[t]{2}{*}{$p$-value } \\
\hline & $\mathrm{n}(\%)$ & Mean \pm SD & \\
\hline Age (years) Classification of age (years) & & $51.08 \pm 9.80$ & \\
\hline $31-40$ & $3(8.3)$ & & $0.318^{\mathrm{a}}$ \\
\hline $41-50$ & $15(41.7)$ & & \\
\hline $51-60$ & $13(36.1)$ & & \\
\hline $61-70$ & $2(5.6)$ & & \\
\hline $71-80$ & $3(8.3)$ & & \\
\hline \multicolumn{4}{|l|}{ Grading differentiation (\%) } \\
\hline Grade 1 & $9(25.0)$ & & $0.000^{\mathrm{a}}$ \\
\hline Grade 2 & $14(38.9)$ & & \\
\hline Grade 3 & $13(41.7)$ & & \\
\hline \multicolumn{4}{|l|}{ Tumor size (\%) } \\
\hline $\mathrm{T} 1$ & $14(38.9)$ & & $0.000^{\mathrm{a}}$ \\
\hline T2 & $7(19.4)$ & & \\
\hline T3 & $15(41.7)$ & & \\
\hline \multicolumn{4}{|l|}{ Estrogen receptor } \\
\hline Positive & $18(50.0)$ & & $0.000^{\mathrm{a}}$ \\
\hline Negative & $18(50.0)$ & & \\
\hline \multicolumn{4}{|l|}{ Progesterone receptor } \\
\hline Positive & $14(38.9)$ & & $0.000^{\mathrm{a}}$ \\
\hline Negative & $22(61.1)$ & & \\
\hline
\end{tabular}

The tumor size was also reclassified into T1 and $\geq \mathrm{T} 2$ to evaluate the risk analysis between tumor size and the expression of estrogen or PR, respectively. There were $15(65.2 \%)$ samples as positive ER expression and about 13 (56.5\%) cases as positive PR expression. $A$ recent study also found that ER and PR expressions were also statistically significant higher expressed in T1 tumor size compared with T2 or above $(p<0.05)$. Positive ER and PR expressions were 4.375 (1.027-18.629) and 6.12 (1.394-26.876) times higher in T1 tumor size group compared to the T2 tumor size (Table 3 ).

Table 2: Risk analysis between ER and PR expression to the degree of differentiation

\begin{tabular}{|c|c|c|c|c|c|c|}
\hline \multirow[t]{2}{*}{ Parameters } & \multicolumn{2}{|c|}{$\begin{array}{l}\text { Degree of } \\
\text { differentiation } n(\%)\end{array}$} & \multirow[t]{2}{*}{ OR } & \multicolumn{2}{|c|}{$\begin{array}{l}95 \% \text { confidence } \\
\text { interval }\end{array}$} & \multirow[t]{2}{*}{$p$-value } \\
\hline & $\leq$ Grade 2 & $>$ Grade 2 & & Lower & Upper & \\
\hline \multicolumn{7}{|l|}{ Estrogen receptor } \\
\hline $\begin{array}{l}\text { Positive expression (+) } \\
\text { Negative expression (-) }\end{array}$ & $15(65.2)$ & $3(23.1)$ & 6.25 & 1.327 & 29.432 & $0.018^{*}$ \\
\hline \multicolumn{7}{|l|}{ Progesterone receptor } \\
\hline Positive expression (+) & $13(56.5)$ & $1(7.7)$ & 15.60 & 1.728 & 140.829 & $0.004^{*}$ \\
\hline Negative expression (-) & $10(43.5)$ & $12(92.3)$ & & & & \\
\hline
\end{tabular}

Histopathological assessment was carried out using hematoxylin-eosin $\mathrm{H}$ and $\mathrm{E}$ ). The sample with $\mathrm{H}$

Table 3: Relationship between ER and PR expression to the tumor size

\begin{tabular}{|c|c|c|c|c|c|c|}
\hline \multirow[t]{2}{*}{ Parameters } & \multicolumn{2}{|c|}{ Tumor size n (\%) } & \multirow[t]{2}{*}{ OR } & \multicolumn{2}{|c|}{$\begin{array}{l}5 \% \text { confidence } \\
\text { interval }\end{array}$} & \multirow[t]{2}{*}{ p-value } \\
\hline & T1 & $\geq T 2$ & & Lower & Upper & \\
\hline \multicolumn{7}{|l|}{ Estrogen receptor } \\
\hline Positive expression (+) & $10(71.4)$ & $8(36.4)$ & 4.375 & 1.027 & 18.629 & $0.043^{*}$ \\
\hline Negative expression (-) & $4(28.6)$ & $14(63.6)$ & & & & \\
\hline \multicolumn{7}{|l|}{ Progesterone receptor } \\
\hline Positive expression (+) & $9(64.3)$ & $5(22.7)$ & 6.12 & 1.394 & 26.876 & $0.016^{*}$ \\
\hline Negative expression (-) & $5(35.7)$ & $17(77.3)$ & & & & \\
\hline
\end{tabular}


and $\mathrm{E}$ staining according to histopathological grade is shown in Figure 1.

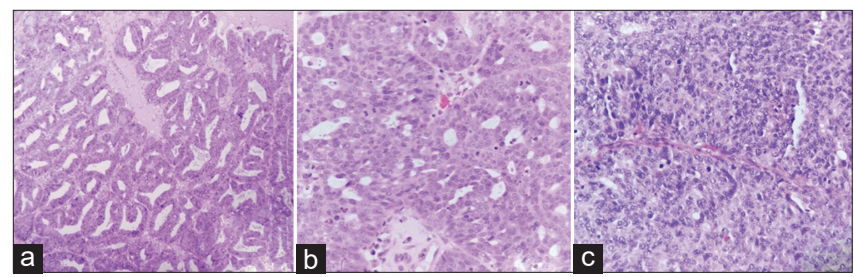

Figure 1: The endometrioid-type ovarian carcinoma $(H E, \times 100)([a]$ Grade 1; [b] Grade 2; [c] Grade 3)

The positive results of immunohistochemical ER staining are shown in Figures 2.

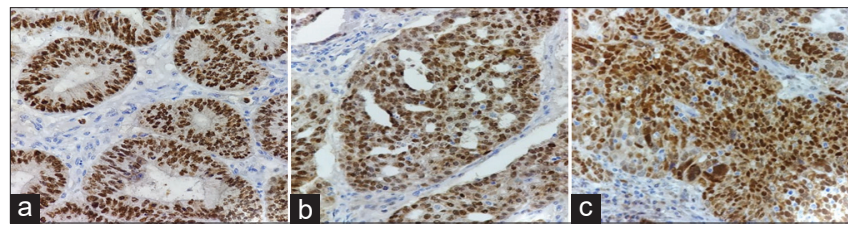

Figure 2: Positive expression of estrogen receptor in endometrioidtype ovarian carcinoma (IHK ER, ×400) ([a] Grade 1; [b] Grade 2; [c] Grade 3)

The positive results of immunohistochemical PR staining are shown in Figures 3.

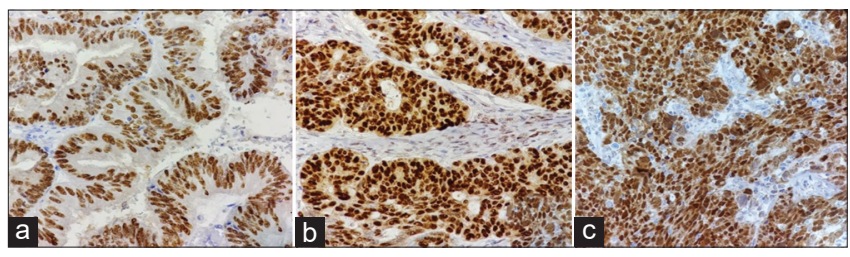

Figure 3: Positive expression of progesterone receptor in endometrioid-type ovarian carcinoma (IHK PR, ×400) ([a] Grade 1, [b] Grade 2; [c] Grade 3)

\section{Discussion}

Epithelial ovarian cancer is a heterogeneous disease, with various subtypes that differ in terms of cell origin, pathogenesis, molecular changes, gene expression, and prognosis. Endometrioid type is found around $10-20 \%$ of all ovarian carcinomas. The other types are high-grade serous (70\%), clear cell (10\%), mucinous $(3 \%)$, and low-grade serous $(<5 \%)$ [8], [9]. In our setting, based on initial study, the prevalence of endometrioid-type carcinoma was also the most common, around 15-25\% among other types. Other studies found the incidence of endometrioid-type ovarian carcinoma only around $7-7.7 \%$, while the other types are $70.5 \%$ serious type, $13.5 \%$ mucinous, and 8.3\% clear cell [6], [12].

A study by Lenhard et al. found that ovarian cancer occurred in the age range of 21-88 years at diagnosed, with an average age of 59 years [6]. In this study, the most age group was $41-50$ years old $(41.7 \%)$, younger than the previous study, but remains in the fifth decade. Based on the degree of differentiation, the most distinctive of ovarian cancer is Grade 2 as many as $36.5 \%$, while Grade 1 and Grade 2 were found as many as $27.2 \%$ and $36.3 \%$, respectively [6]. In a recent study, the most differentiation was also found in Grade 2 (38.9\%).

Endometrioid-type ovarian carcinoma morphologically is similar to its counterpart in the endometrium, and about $50 \%$ is limited to the ovary at the time of diagnosis. In one study, the most stage is found in FIGO Stage III as many as $70.3 \%$ and then $22.6 \%$ Stage I, 5.8\% Stage II, and 1.3\% Stage IV [6]. Another study found that prognosis of ovarian carcinoma tends to be poor because the incidence of tumor at an advanced stage when the first diagnosis is quite high, which is about $75 \%$ of all patients showed FIGO Stage III or IV [2]. In this study, based on the size of the tumor, the most sample was T3 or FIGO Stage III as many as 15 samples $(41.7 \%)$.

The previous study found that there were differences in ER and PR expression among various ovarian cancer subtypes. The highest proportion is the expression in endometrioid-type carcinomas many as $67 \%$, and the second is in low-grade serous carcinoma as many as $58 \%$, the rest is $31 \%$ in high-grade serous carcinoma, $17 \%$ in mucinous carcinoma, and $8 \%$ in clear cell carcinoma [11]. A study by Sieh et al., in 2013, found that positive ER expressions were more than positive PR in all types of ovarian carcinoma. In tumors with positive ER expression and positive PR expression, the most expression was found in the endometrioid type which was as many as $82 \%$ [11]. In line with the previous study, George et al. found that a positive ER expression in epithelial ovarian cancer is also approximately occurred in 43-81\% samples [13]. In another study, which examined the expression of $E R$ and $P R$ isoform (namely, ER- $\alpha, E R-\beta$ and PR-A, PR-B), it was found that ovarian carcinoma was positive for $E R-\alpha /-\beta$ by $31.4 \%$ and $60.1 \%$; and positive for PR-A/-B by $36.2 \%$ and $33.8 \%$. It is similar to the results of another study, i.e. the expression of ER in ovarian cancer is by $32-77 \%$ and by $26-43 \%$ for PR expression [6]. The recent study also found a positive ER and PR expression in 18 samples (50\%) and 14 samples (38.9\%), respectively.

A previous study found that ER- $\alpha$ expression shows significant correlation with grade [2]. In this study, based on the degree of differentiation, the most positive ER expression was found in Grade 2 or below as many as 15 (65.2), while the most negative ER expression was found in Grade 3 as many as 10 samples (76.9\%). Our risk analysis model found that ER expression was 6.25 times higher significantly in Grade 2 or below. A similar result also found on tumor size, whereas the most positive ER expression was found in T1 approximately 10 samples (71.4\%), while the most negative ER expression was found in T2 or more, as many as 14 samples (63.6\%). Our findings also exhibit that ER expression was 4.375 times higher significantly toward tumor size. The recent finding 
suggests that the tumor size which is positively correlated to the grading of cancer also depicted a higher ER expression in ovarian type carcinoma.

Besides ER expression, our study also found a similar result with PR expression. The most positive PR expression was found in Grade 2 (50.0\%), while the most negative PR expression was found in Grade 3 (54.5\%). Our findings suggest that PR expression was predominantly higher on low grade and tumor size several times compared with the negative results (15.60 times higher to the degree of differentiation and 6.12 times higher to the tumor size). Those results are found after reclassified both parameters, degree of differentiation and tumor size.

A study conducted by Sieh et al. revealed that positive ER and PR expressions are associated with increased patient survival. Expression of ER and PR is prognostic biology marker in endometrioid type and high-grade serous type ovarian carcinoma. Patients with positive ER and PR expressions have lower mortality compared to those with negative hormonal expression. The clinical trial, determination of subtype, and status of biological marker are necessary to determine whether the hormonal receptor status can predict the response to endocrine therapy and whether it can be used to identify ovarian cancer therapy individually [6], [11]. The study by Halon et al. found that only $15-18 \%$ of ovarian cancer with positive ER expression responded to anti-estrogen treatment by inhibiting estrogen and ER binding, whereas this therapy was effective in $50 \%$ of breast cancer patients with positive ER expression. Based on these results, the clinician could use this finding to determine their clinical reasoning in therapy, whereas estrogen or progesterone replacement therapy may have a favorable outcome if provided to the earliest degree of differentiation or lower tumor size.

\section{Conclusion}

ER and PR were statistically significant predominantly expressed in the early degree of differentiation and low tumor size among patients with endometrioid-type ovarian cancer at Sanglah General Hospital, Bali, Indonesia. However, as a preliminary study, further investigation with a bigger sample size as well as a different design of study needs to be conducted to clarify the recent findings.

\section{Ethical Clearance}

The ethical approval has been obtained before the study conducted by the Ethics Committee of Udayana University/Sanglah General Hospital, Denpasar, Bali, based on COPE.

\section{Authors' Contributions}

I Gusti Ayu Sri Mahendra Dewi is responsible for developing a concept of the study, data analysis, as well as results interpretation. Ni Putu Ekawati is responsible for the manuscript preparation and histopathological assessment.

\section{Acknowledgment}

We would like to show our gratitude to $\mathrm{Ni}$ Made Dian Hartaningsih and I Putu Yuda Prabawa who provided insight and expertise that greatly assisted the statistical analysis and English improvement of study. We are also thankful to her for their comments on an earlier version of the manuscript as well as editorial help of manuscript.

\section{References}

1. Reid BM, Permuth JB, Sellers TA. Epidemiology of ovarian cancer: A review. Cancer Biol Med. 2017;14(1):9-32. https://doi. org/10.20892/j.issn.2095-3941.2016.0084 PMid:28443200

2. Halon A, Materna V, Drag-Zalesinska M, Nowak-Markwitz E, Gansukh T, Donizy P, et al. Estrogen receptor alpha expression in ovarian cancer predicts longer overall survival. Pathol Oncol Res. 2011;17(3):511-8. https://doi.org/10.1007/ s12253-010-9340-0 PMid:21207255

3. Chen S, Dai X, Gao Y, Shen F, Ding J, Chen Q. The positivity of estrogen receptor and progesterone receptor may not be associated with metastasis and recurrence in epithelial ovarian cancer. Sci Rep. 2017;7(1):16922. https://doi.org/10.1038/ s41598-017-17265-6

PMid:29208958

4. Diep $\mathrm{CH}$, Daniel AR, Mauro LJ, Knutson TP, Lange CA Progesterone action in breast, uterine, and ovarian cancers. J Mol Endocrinol. 2015;54(2):R31-53. https://doi.org/10.1530/ JME-14-0252

PMid: 25587053

5. Prabawa IPY, Bhargah A, Liwang F, Tandio DA, Tandio AL, Lestari AAW, et al. Pretreatment neutrophil-to-lymphocyte ratio (NLR) and platelet-to-lymphocyte Ratio (PLR) as a predictive value of hematological markers in cervical cancer. Asian Pac J Cancer Prev. 2019;20(3):863-8. https://doi.org/10.31557/ APJCP.2019.20.3.863

PMid:30912405

6. Lenhard M, Tereza L, Heublein S, Ditsch N, Himsl I, Mayr D, 
et al. Steroid hormone receptor expression in ovarian cancer: Progesterone receptor B as prognostic marker for patient survival. BMC Cancer. 2012;12:553. https://doi. org/10.1186/1471-2407-12-553

PMid:23176303

7. Stewart CJ, Brennan BA, Chan T, Netreba J. WT1 expression in endometrioid ovarian carcinoma with and without associated endometriosis. Pathology. 2008;40(6):592-9. https://doi. org/10.1080/00313020802320697

PMid: 18752126

8. Kumar V, Abbas AK, Aster JC. Robbins and Cotran Pathologic Basis of Disease. $9^{\text {th }}$ ed. Philadelphia (PA): Elsevier; 2015. p. 1094-5.

9. Burges A, Schmalfeldt B. Ovarian cancer: Diagnosis and treatment. Dtsch Arztebl Int. 2011;108(38):635-41. https://doi. org/10.3238/arztebl.2011.0635

PMid:22025930

10. Kurman JR, Carcangiu ML, Herrington CS, Young RH. WHO
Classification of Tumor of Female Reproductive Organs. $4^{\text {th }}$ ed. Lyon: International Agency for Research on Cancer (IARC); 2014. p. 17-83

11. Sieh W, Köbel M, Longacre TA, Bowtell DD, deFazio A, Goodman MT, et al. Hormone-receptor expression and ovarian cancer survival: an Ovarian Tumor Tissue Analysis consortium study. Lancet Oncol. 2013;14(9):853-62. https://doi.org/10.1016/ S1470-2045(13)70253-5

PMid:23845225

12. Cho KR, Shih leM. Ovarian cancer. Annu Rev Pathol. 2009;4:287313. https://doi.org/10.1146/annurev.pathol.4.110807.092246 PMid:18842102

13. George A, McLachlan J, Tunariu N, Della Pepa C, Migali C, Gore $\mathrm{M}$, et al. The role of hormonal therapy in patients with relapsed high-grade ovarian carcinoma: A retrospective series of tamoxifen and letrozole. BMC Cancer. 2017;17(1):456. https://doi.org/10.1186/s12885-017-3440-0

PMid:28666422 